\title{
Influence of Dye Loading Time and Electrolytes Constituents Ratio on the Performance of Spin Coated ZnO Photoanode Based Dye Sensitized Solar Cells
}

\author{
AMRIK SINGH $^{1 *}$, DEVENDRA MOHAN ${ }^{2}$, DHARAMVIR S. AHLAWAT ${ }^{1}$ and RICHA ${ }^{3}$ \\ ${ }^{1}$ Material Science Lab., Department of Physics, Chaudhary Devi Lal University, \\ Sirsa-125055 Haryana India. \\ 2Laser Laboratory, Department of Applied Physics, Guru Jambheshwar University of Science \\ \&Technology, Hisar-125001, Haryana, India. \\ ${ }^{3}$ Research Scholar, Department of Physics, I.K.Gujral Punjab Technical University, \\ Jalandhar, Punjab, India. \\ *Corresponding author E-mail: amrik23kuk@gmail.com \\ http://dx.doi.org/10.13005/ojc/320229
}

(Received: February 16, 2016; Accepted: April 04, 2016)

\begin{abstract}
$\mathrm{ZnO}$ photoanodes for dye sensitized solar cell were sythesized by using sol-gel spin coating method. XRD pattern confirmed that ZnO film was crystalline in nature and crystallite size calculated was $45.8 \mathrm{~nm}$. The grain size measured form SEM image of $\mathrm{ZnO}$ film was $66.6 \mathrm{~nm}$. Transmission of thin film was observed $75-92 \%$ in wavelength range from $400-800 \mathrm{~nm}$. The photon to electron conversion effieciency for dye loaded 6 and 12 hours time were obtained $0.38 \%$ and $0.44 \%$ respectively. In case of electrolytes ratio, the maximum effieciency and fill factor of DSSCs were found $0.44 \%$ and 0.49 respectively.
\end{abstract}

Keywords: $\mathrm{ZnO}$ sol, $\mathrm{ZnO}$ thin films, Dye loading time, Electrolytes ratio and Dye sentized solar cells.

\section{INTRODUCTION}

Dye sensitized solar cells (DSSC) have attracted considerable attention in recent years as an alternative to conventional silicon solar cells ${ }^{1-8}$. Dye sensitized solar cell consist of photoelectrode, counterelectrode and electrolytes. Transparent conducting oxide/glass like ITO(indium doped tin oxide), FTO (Flourine doped tin oxide) that act substrates for both photoanode and counterlectrode. Photoanode consists of $\mathrm{ZnO}$ film coated on ITO glass substrate. As incident photons are absorbed by dye molecules, then consequetly electrons injected from their excited states into the conduction band of the $\mathrm{TiO}_{2} / \mathrm{ZnO}$ nanoparticles and the dye molecule gets oxidized. Oxidized dye molecules are reduced by a redox electrolyte, which transports the positive charges by diffusion to a counterelectrode ${ }^{9-15}$. The 
$\mathrm{ZnO}$ material possesses a wide band gap, low resistance and high light trapping characteristics that make it suitable in solar cells applications ${ }^{16-}$ ${ }^{23} \mathrm{~A}$ high electron diffusion coefficient and a low recombination rate constant are key requirements for fabricating highly efficient dye-sensitized solar cells. Higher dye loadings, which are desirable for inducing higher photon harvesting, are also limited by the low diffusion and high recombination rates of the electrons ${ }^{24,25}$. In the present paper we have focused on effieciency variation of DSSC with change in concnetration of lithium iodidie in electrolytes and dye loading time of $\mathrm{ZnO}$ photoanode. Dye loaded in semiconductor oxide film becomes essential to improve the light harvesting efficiency of a DSSC material. A monolayer and uniform dye coverage are highly to enhance performance. In fact, multilayer formation and poor dye coverage hinder the kinetics of electron transfer ${ }^{26}$.

\section{EXPERIMENTAL}

\section{Materials used}

Zinc accetate dihydrate (sigma aldrich) as Zinc precursor, ethanol (merck), ethanolamine, Lithium iodide (sigma aldrich 99.9\%), iodine(sigma aldrich $99.9 \%$ ), platinum tetrachloride (sigma aldrich 99.9\%), acetonirile (sigma aldrich $99.9 \%$ ) and ITO(indium doped tin oxide) sheets as substrates for both photoanode and counterlectrode.

\section{$\mathrm{ZnO}$ sol preparation}

$\mathrm{ZnO}$ sol was prepared from zinc accetate dihydrate, ehtanol. $50 \mathrm{ml}$ ethanol was taken into conical flask maintained at $60^{\circ} \mathrm{C}$ temperature. Zinc accetate dihydrate $(0.8 \mathrm{M})$ was added into stirred ethanol, after 30 minutes pour the ehtanolamine as stabilizerinto solution dropwise. The molar ratio of zinc accetate and ehtanolamine was matained at 1:1. After 30 minutes of stirring cool down the transparent $\mathrm{ZnO}$ sol was obtained. Sol was allowed to stand at room temperature for 24 hours before coating.

\section{Photoanode and counter electrode preparation}

$\mathrm{ZnO}$ sol was deposited on ITO substrates by using spin coater (MTI Corporation). The speed of spin coater was adjusted to 3000rpm for one minute. After each coating, the film was exposed $180^{\circ} \mathrm{C}$ for 10 minutes for removal of extra solvents. For desire thickness of films the steps of coating were repeated and then samples were annealed at $550^{\circ} \mathrm{C}$ with ramp rate $10^{\circ} \mathrm{C} / \mathrm{min}$. temperature for one hour. For preparation of counterelectrodes, platinum film coated ITO the solution was made from $5 \mathrm{mM}$ $\mathrm{PtCl}_{4}$ (Sigma Aldrich 99.9\%) in isoproponal (Sigma Aldrich). Solution was deposited on ITO glass substrate and spin for $1 \mathrm{~min}$ at $2800 \mathrm{rpm}$ speed. Heat the platinum film at $130^{\circ} \mathrm{C}$ for 15 minutes at hot plate and annealed at $400^{\circ} \mathrm{C}$ for 15 minutes in furnace.

\section{Electrolytes solution preparation}

Electrolytes solution was made from $0.03 \mathrm{M}$ Lithium lodide (Sigma Aldrich 99.9\%), 5mM iodine (SigmaAldrich) in acetonitrile (Sigma Aldrich) to form solution EL1 ( $L i l: I_{2}=6: 1$ ) and solution made from $0.05 \mathrm{M}$ Lithium lodide and $5 \mathrm{mM}$ iodine in acetonitrile to form EL2 ( $\left.\mathrm{Lil}: \mathrm{I}_{2}=10: 1\right)$.

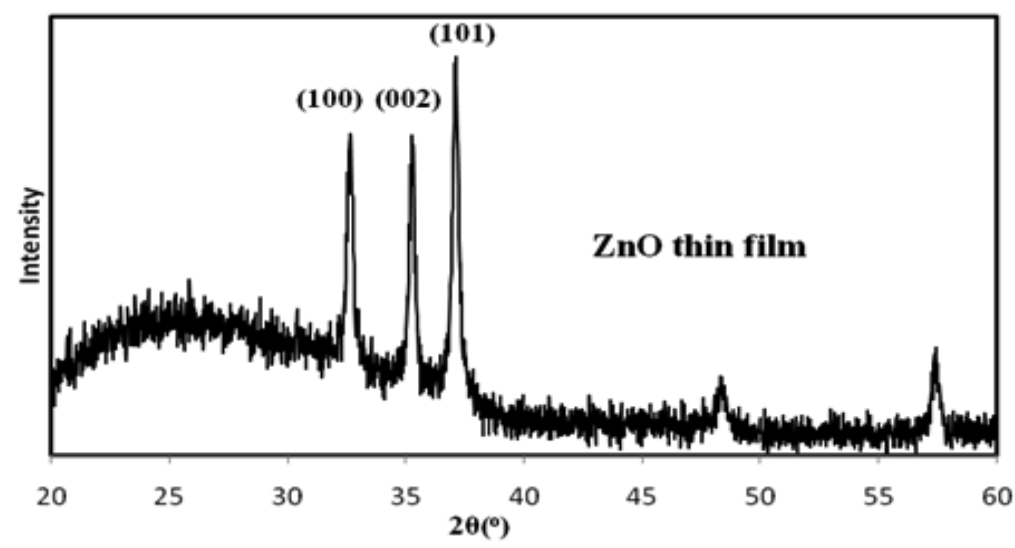

Fig.1: XRD pattern of ZnO film 


\section{Dye loading of photoanodes and assembling} of DSSCs

0.5mM N719 dye (Sigma Aldrich 99.9\%) and ethanol (Merck) were mixed to form dye solution. Dipped the ZnO film coated ITO photoanodes in dye solution for 6 hours(DP1), 12 hours (DP2) and washed with ethanol to remove extra dye. In case of EL1 and EL2 based DSSCs, the photoanode was dipped in 0.5mM N719 dye (Sigma Aldrich 99.9\%) and ethanol (Merck) solution (DP2) for 12 hours and the excessive dye was washed away by using ethanol. The EL2 (Lil : $\left.I_{2}=10: 1\right)$ combination of electrolytes was used in DP1 and DP2 photoanodes based DSSCs.

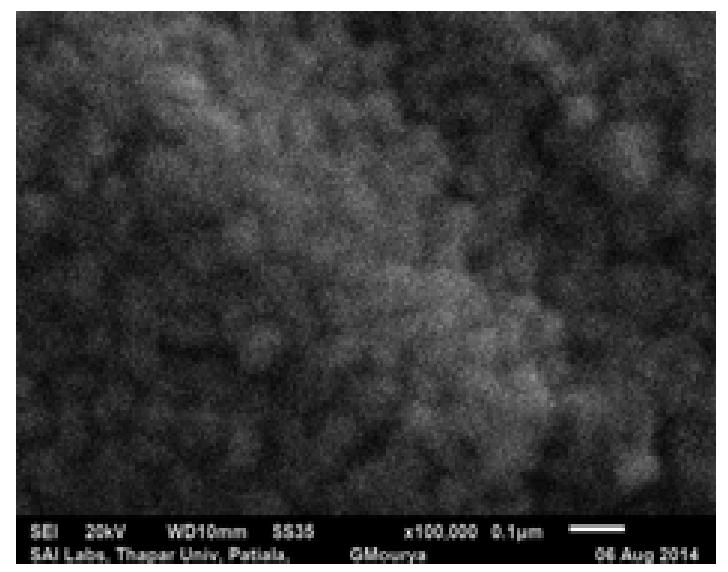

Fig. 2: SEM image of ZnO film

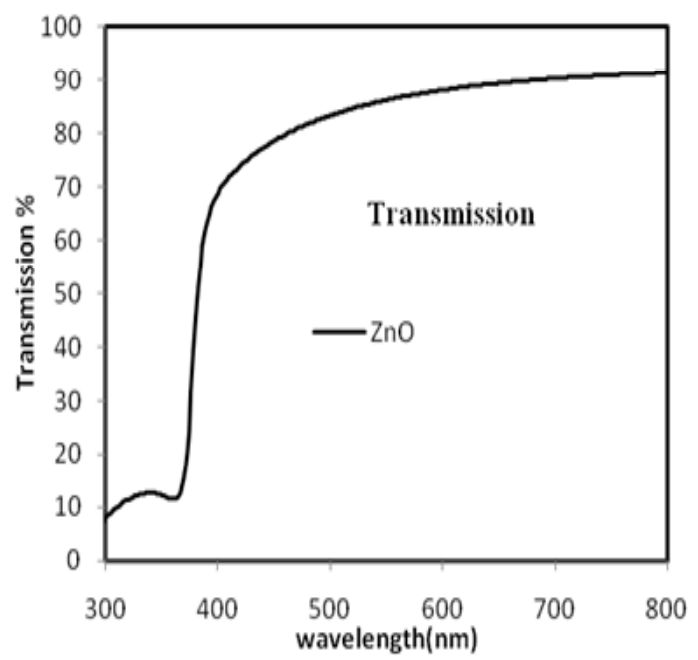

Fig. 3: Transmission spectra of ZnO film
Combined the photoanode and conterlectrode together and injected the electrolytes between the electrodes. A sandwich-type DSSC configuration was fabricated.

\section{Characterization techniques}

$\mathrm{XRD}$ analysis of $\mathrm{ZnO}$ film were carried out by XRD model (Rigaku). SEM and UV-Visible of $\mathrm{ZnO}$ sample was investigated by SEM (SEM, JEOL) and (SHIMAZDU, UV) respectively. The photocurrent-voltage $(\mathrm{J}-\mathrm{V})$ characteristics of solar cell were measured using a AM-1.5 solar simulator with xenon lamp (max.150 W) ar room temperature. Incident light intensity and active cell area were 100 $\mathrm{mW} / \mathrm{cm}^{+2}$ and $1 \mathrm{~cm} \times 1 \mathrm{~cm}$ respectively.

\section{RESULTS AND DISCUSSIONS}

Fig.1 demonstrates the XRD paatern of $\mathrm{ZnO}$ film obtained in angle range of $20-60^{\circ}$. The main peaks of XRD corresponding to (100), (002) and $(101)$ at $32.68^{\circ}, 35.34^{\circ}$ and $36.68^{\circ}$ angles respectively. The high intense peak at (101) coorespondes to $36.68^{\circ}$ angle(2è). The full width at half maximum (â) of the diffraction peak can be used to estimate the crystallite size (D) in the grown $\mathrm{ZnO}$ films using Scherrer's formula ${ }^{27}$

The crystallite size corresponding to (101) plane of $\mathrm{ZnO}$ film was $45.8 \mathrm{~nm}$.

Fig. 2 shows the SEM image of ZnO film. It is evident that there is a regular arrangement

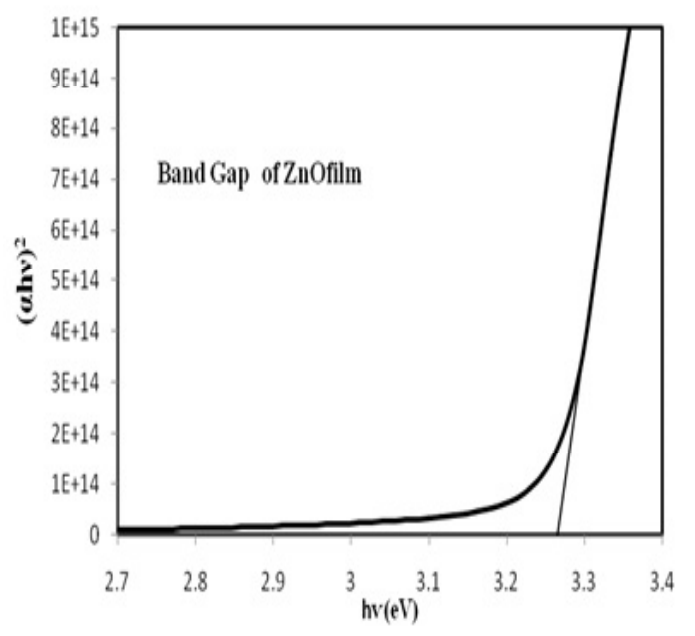

Fig. 4: Band gap of $\mathrm{ZnO}$ film 
of grains. The average grain size of $\mathrm{ZnO}$ film was obtained as $66.6 \mathrm{~nm}$.

Fig. 3 shows the Uv-Visible spectra of $\mathrm{ZnO}$ film in the wavelength range of $300-800 \mathrm{~nm}$.
The transmission of $\mathrm{ZnO}$ film was $75-90 \%$ in wavelength from $400-800 \mathrm{~nm}$. The maximum value of transmission was observed at wavelength $800 \mathrm{~nm}$. The optical absorption coefficient can be calculated by lambert law relation ${ }^{28}$

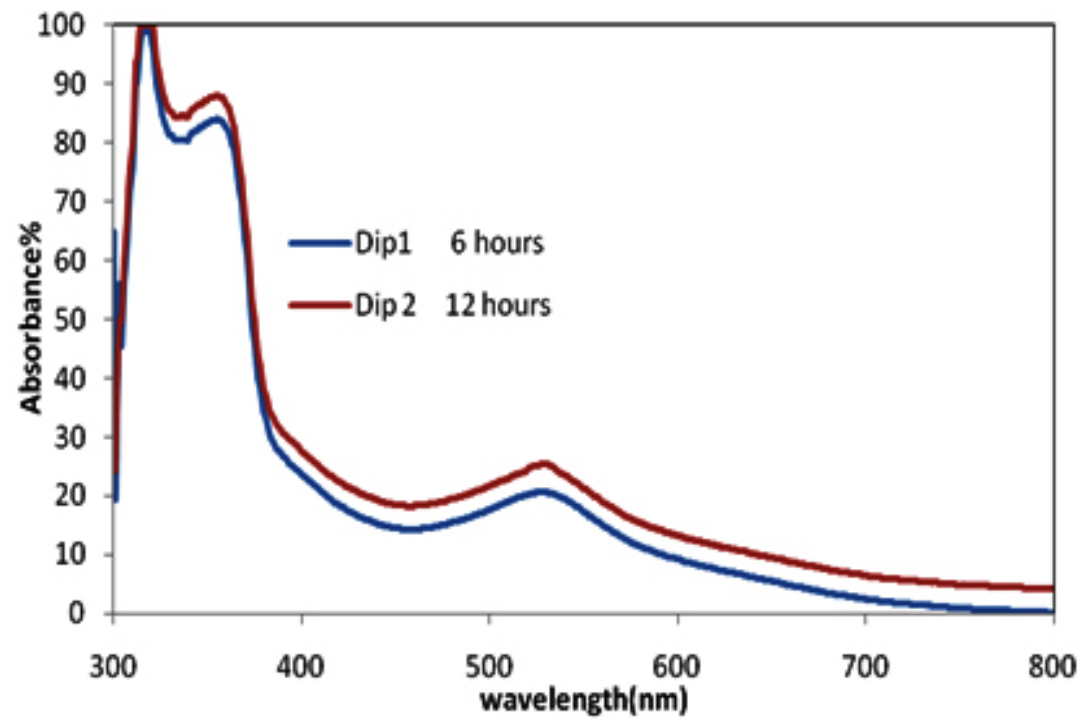

Fig. 5: Uv-Visible absorbance of dye loaded ZnO films

Table 1: Demonstrates The Photovoltaic Performance of Different Samples of Zno DSSC

\begin{tabular}{|c|c|c|c|c|}
\hline Sample & Fill factor & Voc (mV) & $\mathrm{Jsc}(\mathrm{mA} / \mathrm{cm} 2)$ & Efficiency \% \\
\hline Dip1 6 hours & 0.47 & 580 & 1.4 & 0.38 \\
\hline Dip2 12 hours & 0.49 & 600 & 1.5 & 0.44 \\
\hline EL1 & 0.46 & 590 & 1.35 & 0.36 \\
\hline EL2 & 0.49 & 600 & 1.5 & 0.44 \\
\hline
\end{tabular}

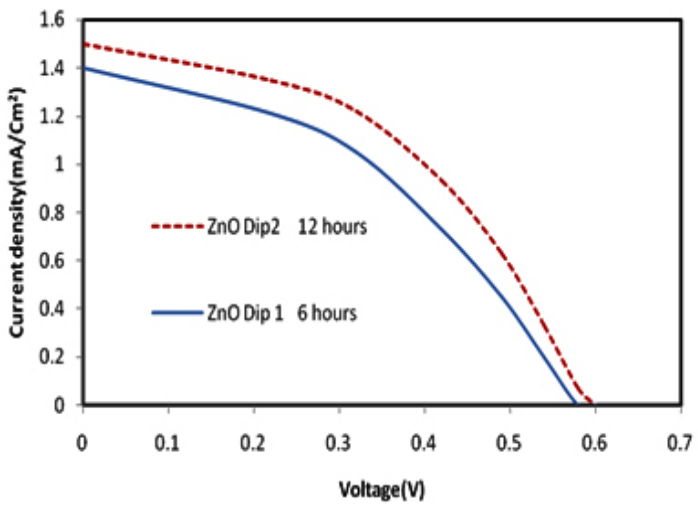

Fig. 6: J-V characteristics of dip 1 and dip2 photoanode based solar cell

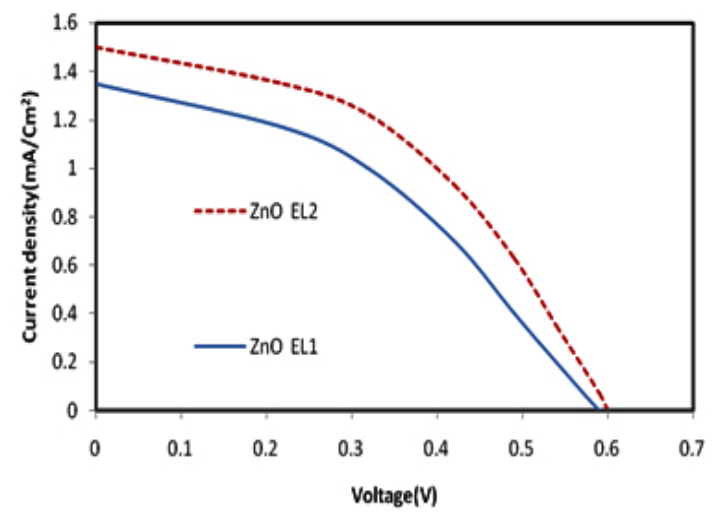

Fig. 7: J-V characteristics of EL1 and EL2 based solar cell 
where $d$ is the thickness and $T$ is the transmittance of $\mathrm{ZnO}$ film. The relation between absorption coefficient and incident photon energy can be written as:

$$
\alpha h v=A\left(h v-E_{g}\right)^{1 / 2}
$$

Where $A$ is a constant, $E_{g}$ is the band gap of the material and $\mathrm{h}$ is the planks constant. In the present case, the plot of (áhv) ${ }^{2}$ verus hv, indicates the direct band gap nature of the films. By extrapolating the linear portion of the curve onto the $\mathrm{X}$ axis the energy band gap of the films was determined. Fig. 4 shows the band gap of $\mathrm{ZnO}$ film. The band gap calculated investigated from tauc's plot was 3.269 $\mathrm{eV}$.

Fig.5 investigated the Uv-Visible absorbance of N719 dye loaded films for 6 hours and 12 hours in the wavelength range of $300-800 \mathrm{~nm}$. The main absorbance peaks at around wavelength $310 \mathrm{~nm}$, $371 \mathrm{~nm}$ and $532 \mathrm{~nm}$. However, the absorbance of 12 hours dye loaded $\mathrm{ZnO}$ film (DP2) was high as compared to $\mathrm{ZnO}$ film loaded in dye for 6 hours (DP1) at room temperature.

\section{Performance OF DSSCS}

The values of fill factor (FF) and efficiency of DSSC were calculated by following equations 1 and 2

$$
\mathrm{FF}=\mathrm{I}_{\mathrm{m}} \times \mathrm{V}_{\mathrm{m}} / \mathrm{I}_{\mathrm{sc}} \times \mathrm{V}_{\mathrm{oc}}
$$

Here $V_{o c}, I_{s c}, I_{m}$ and $V_{m}$ are open circuit voltage, short circuit current, maximum current and maximum voltage respectively.

$$
\eta=I_{s c} x V_{o c} x F F / P_{\text {in }}\left(m W / \mathrm{cm}^{2}\right)
$$

$\eta$ is the efficiency of solar cell, $P_{\text {in }}$ is the input power provided to DSSC.

To calculate the energy conversion efficiency, the current vs. voltage relation was measured. Fig. 6 demonstrates the $\mathrm{J}-\mathrm{V}$ characteristics of DSSCs with dip and dip2. The highest value of open circuit voltage was $600 \mathrm{mV}$ for DP2 DSSC. The calculated fill factor of DP1 and DP2 photoelectrode based DSSC were 0.47 and 0.49 respectively. The conversion efficiency values for DP1 and DP2 were observed $0.38 \%, 0.44 \%$ respectively. For all film thicknesses with $310 \mathrm{~nm}$, the energy conversion efficiency inferred from the current-voltage curves presented in these graph increases as the dye-loading times increase. The enhancement in photon to electron conversion performance of DSSC was due to harvest in large number of photons in DP2 as compared to DP1 ${ }^{29}$.

Fig.7 shows the J-V characteristics of DSSCs with EL1 and EL2. Highest current density was $1.5 \mathrm{~mA} / \mathrm{cm}^{2}$ in case of EL2 sample. The fill factor for EL1 and EL2 based DSSCs were analyzed 0.45 and 0.49 respectively. The calculated efficiency for DSSCs with EL1 and EL2 combinations were $0.36 \%, 0.44 \%$ respectively. Excess Lil causes the penetration of $\mathrm{Li}^{+}$ions in the mesoporous dye-coated nanocrystalline $\mathrm{ZnO}$ film due to its small-radius and form an ambipolar $\mathrm{Li}^{+}$- e" with the electrons in the conduction band of $\mathrm{ZnO}$, which increases the transport speed of electrons in nanocrystalline $\mathrm{ZnO}$ network and enhances the $\mathrm{J}_{\mathrm{sc}}$ of DSSCs ${ }^{30-33}$

\section{CONCLUSIONS}

In this work dye sensitized solar cell with a photoanodes of $\mathrm{ZnO}$ films coated ITO/Glass substrates were fabricated and characterized. The $\mathrm{ZnO}$ films were prepared using spin coating process. The grain size calculated from SEM was $44 \mathrm{~nm}$. The band gap value of $\mathrm{ZnO}$ was observed $3.269 \mathrm{eV}$. Our studies have revealed that there was a variation in efficiency of DSSCs with different dye loading time and different ratio of Lithium iodide and iodine in electrolytes solution. The highest energy conversion efficiency of DSSC at dye loading time of 12 hours and electrolytes combination EL2. The fill factor values for DSSCs with DP1, DP2, ELI and EL2 were investigated $0.47,0.49$ and 0.45 and 0.49 respectively. The electron to photon energy conversion efficiency \% values for DP1, DP2, EL1 and EL2 based DSSCs were measured 0.38, 0.44, 0.36 and 0.44 respectively.

\section{ACKNOWLEDGEMENT}

Financially and experimental support from Inter- University Accelerator Centre (An autonomous centre of UGC), New Delhi is gratefully acknowledged. 


\section{REFERENCES}

1. Regan B.O., Grätzel M., Nature 1991, 353, 737.

2. Gratzel M., Nature 2001, 414, 338.

3. Nazeeruddin M.K., Angelis F.D., Fantacci S., Selloni A., Viscardi G., Liska P., Ito S., Grätzel M. , J. of the American Chem. Soc. 127 (2005) 16835.

4. Afifi A., Tabataet M.K., Orient. J. Chem. 2014, 30(1), 2024

5. Anta J.A., Guillén E., Tena-Zaera R., J. Phys. Chem. C 2012, 116 (21), 11413-11425

6. Gratzel M, J Photoch Photobio C: Photochem Rev. 2003, 4, 145-153.

7. Zi M., Zhu M., Chen L., Wei H., Yang X, Cao B.Ceram. 2014, Int., 40, 7965-7970.

8. Singh A., Mohan D., Ahlawat D.S., Jyoti D., Materials Sci. Forum 2014, 771, 115-119.

9. Ngaffo F.F., Caricato A.P., Fernandez M., Appl. Surf. Sci. 2007, 253, 6508-6511.

10. Gratzel, M., J. Photochem. Photobiol. 2004, A 164, 3-14.

11. Sharma M., Gairola R.P., Orient. J. Chem., 2013, 29(3), 304.

12. Konenkamp R., Word R.C. and Schlegel C .Appl. Phys. Lett. 2004, 85, 6004-6.

13. Goldberger J., Sirbuly D.J., Law M., and Yang P., J. Phys. Chem. B., 109: 9-14 (2005)

14. Kao M. C., Chen H. Z., Young S. L., Applied Physics A 98(3), 2010, 3, 595-599.

15. Ito S., Murakami T., Comte P., Liska P, Gratzel C., Nazeeruddin M., Gratzel M. Thin Solid Films 2008, 516, 4613-4619.

16. Longo C., Paoli M.A.D., J. Braz. Chem. Soc. 2003, 14, 889-901.

17. Moorthi V.S., Joe J.P.M., Orient. J. chem. 2015, 31(1), 149-157.
18. Gratzel M., Prog. Photovoltaics 2000, 11, 171-185.

19. Jyoti D., Mohan D. and Singh A, Int. J. of Enhanced Research in Sc. Tech. \& Eng. 2014, 3(2), 388-393.

20. Snaith H. J., Adv Funct Mater. 2010, 20, 13-19.

21. Zhang Q., Cao G., Nano Today 2011, 6: 91-109.

22. Zhang Q., Dandeneau C.S., Zhou X., Cao G., Adv Mater. 2009, 21, 1-22.

23. Lee C.H., Chiu W.H., Lee K.M., Yen W.H., Lin H.F., Hsieh W.F., Wu J.M., Electrochim Acta 2010, 55, 8422-8429.

24. Law M., Greene L. E., Johnson J. C., Saykally R., and Yang P., Nature Materials 2005, 6, 455-459.

25. Law M., Greene L.E., Radenovic A., Kuykendall T., Liphardt J. and Yang P., J. of Physical Chem. B 2006, 110( 45), 22652-22663.

26. Ono T., Yamaguchi T., and Arakawa H., J. of Solar Energy Eng. 2010, 132( 2).

27. Ismail A., Abdulla M.J., J. of King Saud Uni. - Sci. 2013, 25, 209-215.

28. Urbach. F., Phys. Rev. 1953, 92, 1324.

29. Rajab F. M., J. of Minerals and Materials Characterization and Eng. 2014, 2, 169-175. 2014.

30. Olson C.L., J. of Phys. Chem.B 2006, 110, 9619.

31. LiuY., Hagfeldt A. , Xiao X.R, Lindquist S.E., Solar Energy Materials and Solar Cells 1998, 55, 267.

32. Enright B., Redmond G., Fitzmaurice D., J. of Physical Chem. 1994, 98, 6195.

33. Lagemaat J.V.D., Park N.G., Frank A.J., J. of Physical Chem. B 2004, 104, 2044. 